\title{
Sleep Apnea in Type 2 Diabetes
}

Jimmy Doumit and Bharati Prasad

Jesse Brown VA Medical Center and University of Illinois at Chicago, Chicago, IL

Corresponding author: Bharati Prasad, bpradsad@uic.edu

DOI: 10.2337/diaspect.29.1.14

(C)2016 by the American Diabetes Association. Readers may use this article as long as the work is properly cited, the use is educational and not for profit, and the work is not altered. See http:// creativecommons.org/licenses/by-nc-nd/3.0 for details.

IN BRIEF Obstructive sleep apnea (OSA) alters glucose metabolism, promotes insulin resistance, and is associated with development of type 2 diabetes. Obesity is a key moderator of the effect of OSA on type 2 diabetes. However, chronic exposure to intermittent hypoxia and other pathophysiological effects of OSA affect glucose metabolism directly, and treatment of OSA can improve glucose homeostasis.<smiles>O</smiles>
bstructive sleep apnea (OSA) is a common chronic respiratory disorder characterized by sleep-induced recurrent upper airway collapse. The prevalence of symptomatic OSA is estimated to be $2-4 \%$ in the general population, in both children and adults $(1,2)$. Pathophysiological consequences of upper airway collapse include intermittent hypoxia and sleep fragmentation, resulting in sympathetic activation, systemic inflammation, and oxidative stress. These perturbations underlie the increased cardiometabolic morbidity and mortality observed in populations with OSA $(3,4)$. OSA has been shown to increase the risk and severity of type 2 diabetes independent of age and obesity. This is notable because age and obesity are risk factors for both OSA and type 2 diabetes. There are limited data on the relationship of OSA to type 1 diabetes and the cardiometabolic impact of OSA in children $(5,6)$. Recent studies suggest that treatment of OSA with continuous positive airway pressure (CPAP) therapy reduces insulin resistance and improves glycemic control in patients with prediabetes or type 2 diabetes.
This article focuses on the effects of OSA and its treatment on glucose metabolism in adults with prediabetes or type 2 diabetes. Data supporting screening, diagnosis, and treatment of OSA in patients with prediabetes or type 2 diabetes are outlined. Finally, the impact of CPAP therapy on diabetes care is discussed.

\section{Insulin Resistance and $\beta$-Cell Dysfunction in OSA}

\section{Mechanisms}

Figure 1 elucidates the biological pathways through which OSA leads to abnormal glucose homeostasis and the clinical conditions of prediabetes and type 2 diabetes.

Intermittent hypoxia (IH) in animal models has been shown to decrease insulin sensitivity (measured via glucose tolerance test [GTT]) and increase the homeostatic model assessment (HOMA) index (7-9). IH affects hepatocytes directly, resulting in increased cellular glycogen content and gluconeogenic enzymatic activity (9). Prolonged periods of $\mathrm{IH}$ exposure in mice cause an increase in proinflammatory cytokines (interleukin-1 $\beta$, interleukin-6, and macrophage inflammatory protein 2) and transcription factor nuclear 


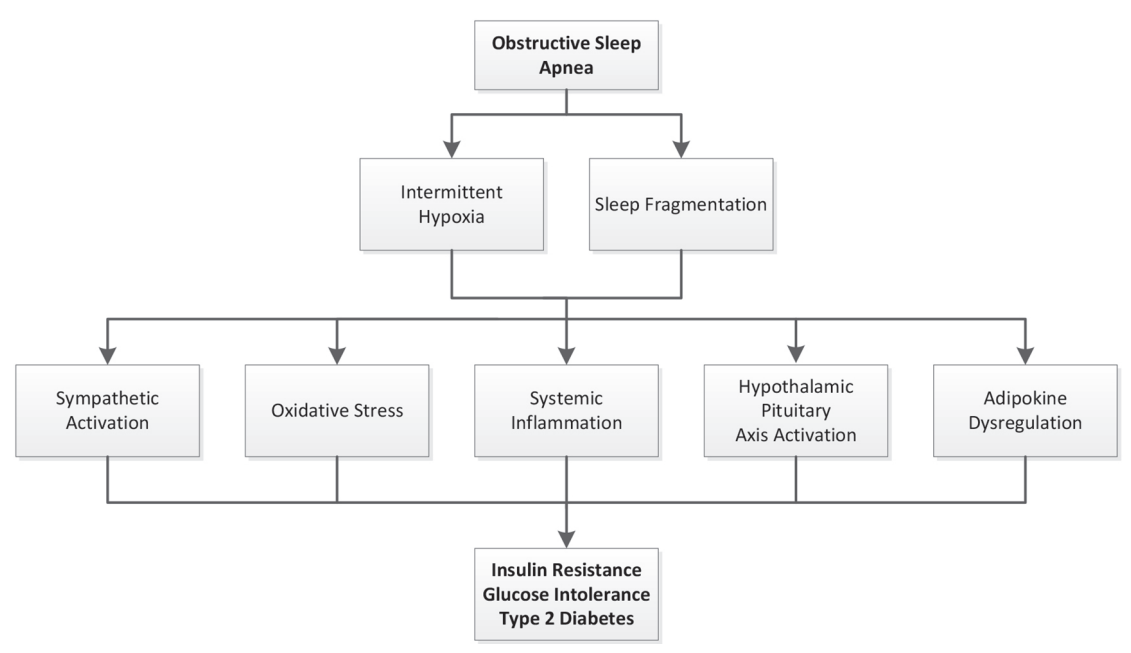

FIGURE 1. Mechanisms of glucose intolerance and type 2 diabetes in OSA.

factor- $\kappa \mathrm{B}(10)$. Reduction in proliferation and apoptosis of pancreatic $\beta$-cells and reduced conversion of proinsulin to insulin has been observed in response to IH in mice (11-13). Adipose tissue is also affected by $\mathrm{IH}$, with downregulation of adiponectin, an insulin-sensitizing hormone, and an increase in resistin $(14,15)$. Finally, IH has been observed to be associated with sympathetic activation in both animal models and humans $(16,17)$. Louis and Punjabi (18) studied healthy adults under conditions of normoxia and after 5 hours of $\mathrm{IH}$ exposure during wakefulness. IH was induced at a rate of 24 per hour, simulating moderate OSA. Intravenous GTT results showed a decrease in insulin sensitivity and glucose effectiveness (i.e., blood glucose-induced suppression of hepatic glycogenesis and increased tissue glucose uptake). Sympathetic activation (i.e., increased heart variability) by hypoxia was also noted, but pancreatic insulin secretion and serum cortisol levels remained unchanged.

Sleep fragmentation (SF; electroencephalographic activation in response to intrathoracic pressure changes against an occluded airway and to hypoxia) affects glucose homeostasis. SF induced in rodent models leads to adiposity, insulin resistance, and hyperglycemia via increased cortisol and biomarkers of inflammation and oxidative stress. SF and $\mathrm{IH}$ are associated with insulin resistance in young adults independent of age and obesity (19). Experimentally induced SF and reduction in slow-wave (i.e., deep) sleep in healthy adults causes decline in insulin sensitivity $(20,21)$. Similarly, SF in the setting of OSA and in patients with type 2 diabetes interferes with glucose homeostasis $(22,23)$.

\section{Epidemiology}

The mechanisms of insulin resistance and pancreatic $\beta$-cell dysfunction, as discussed above, explain the epidemiological observations that the prevalence of prediabetes and type 2 diabetes are increased in OSA. Most studies have used quantitative and validated measures for diabetes and OSA, such as fasting glucose or GTT and polysomnography, respectively. Interestingly, there is evidence to suggest that type 2 diabetes independently increases the likelihood of sleep-disordered breathing (24), possibly through the effects of diabetes on the autonomic and central nervous system. The prevalence of OSA in people with type 2 diabetes is variable, and estimates range from $18 \%$ in primary care (25), to $58 \%$ in an older cohort (24), and as high as
$86 \%$ in obese populations with type 2 diabetes (26).

\section{OSA, Prediabetes, and Type 2} Diabetes

Several cross-sectional studies have shown that OSA is associated with impaired glucose tolerance independent of obesity (27-29), and the risk is strongly associated with the severity of nocturnal hypoxia (30). A longitudinal study of a communitydwelling cohort of men without diabetes showed that OSA was an independent predictor of the development of insulin resistance (31). Longitudinal cohort studies from North America, Europe, and Australia found an overall increased risk of incident diabetes, particularly in moderate to severe OSA (32-35). These findings are further supported by a recent meta-analysis estimating that the risk for incident diabetes in the setting of moderate to severe OSA was increased by 63\% (36). However, there is heterogeneity in the findings of these longitudinal studies when adjusted for confounders, including age, sex, and BMI. This suggests that shared risk factors are important moderators of the association between OSA and type 2 diabetes and should be considered in the clinical evaluation and management decisions pertaining to individual patients. In this regard, emerging data suggest that OSA expression in rapid eye movement (REM) sleep (in which more frequent respiratory events and more severe oxygen desaturation may be observed) has significant effects on insulin resistance and glycemic control $(37,38)$.

\section{Effects of OSA on Type 2 Diabetes}

\section{Metabolic Control}

Several cross-sectional studies have found a detrimental impact of untreated OSA on glycemic control in type 2 diabetes (38-41). Aronsohn et al. (40) prospectively examined the relationship between polysomnography-derived apnea hypopnea index 
(AHI), the gold-standard measure of OSA severity, and $\mathrm{A} 1 \mathrm{C}$ in 60 people with type 2 diabetes. There was a significant positive correlation between $\mathrm{AHI}$ and $\mathrm{A} 1 \mathrm{C}$ after controlling for multiple confounders. Notably, this study reported that the effect size of $\mathrm{AHI}$ on $\mathrm{A} 1 \mathrm{C}$ was greater than that of some antidiabetic drugs. In contrast, the largest prospective analysis of a substudy (Sleep AHEAD [42], involving 305 of 5,145 participants from 4 of 16 centers) failed to show a relationship between AHI derived from polysomnography and A1C. Only a weak correlation was found between fasting glucose and sleep efficiency (a measure that is partly indicative of sleep fragmentation). This study included more obese, older individuals with a longer duration of diabetes, which may account for the discrepant findings. Tamura et al. (43) showed that, although in glucose-intolerant patients AHI predicts long-term glucose control measured by A1C, lowest oxygen saturation appears to correlate better with $\mathrm{A} 1 \mathrm{C}$ in people with type 2 diabetes. Overall, these data support the notion that OSA, particularly moderate to severe OSA, is associated with poorer metabolic control in patients with type 2 diabetes.

\section{Organ System Dysfunction}

OSA leads to increased cardiovascular disease (CVD). The mechanisms underlying vascular dysfunction in OSA include sympathetic activation and oxidative stress (from intermittent hypoxia, hypercapnia, and arousals). These perturbations result in reduced production of endothelium-dependent vasodilators such as nitric oxide (44). Moreover, OSA is associated with a proinflammatory and hypercoagulable state-another pathway that causes vascular injury (45). These mechanisms explain the observation that OSA severity, as indicated by AHI, is significantly associated with risk of stroke (odds ratio 2.5 ) in patients with type 2 diabetes (46). It should be noted that this study included older and obese populations with a high prevalence of OSA (86\%). The independent effects of OSA on CVD should be further examined in lean and younger populations with type 2 diabetes.

There are limited empirical data regarding acceleration of other organ system dysfunction in patients with type 2 diabetes as a result of OSA. OSA leads to progression of chronic kidney disease independently, and this effect is compounded in patients with diabetes (47). A Japanese study evaluated a cohort of -500 patients with type 2 diabetes using nocturnal oximetry for $\mathrm{IH}$ used as a screening test for OSA (48). The researchers found that significant nocturnal hypoxia (in the range seen in OSA) was associated with increased prevalence of hypertension, hyperlipidemia, microalbuminuria, and macroalbuminuria. Notably, this association was robust and significant after adjustment for confounding factors only in women. Similar findings have been reported in super-obese British populations with type 2 diabetes, suggesting that this effect is independent of obesity (49). A recent systematic review and meta-analysis reported a significant association between OSA severity and increased risk of diabetic kidney disease, with an overall odds ratio of 1.73 (50).

A cross-sectional study of $>200$ patients examined the prevalence and possible mechanisms of peripheral neuropathy in a clinic population of people with diabetes, with and without OSA. The prevalence of peripheral neuropathy, particularly severe neuropathy, was higher in patients with OSA. Moreover, nitrotyrosine and lipid peroxide levels (biomarkers of nitrosative and oxidative stress) were elevated in the OSA group and correlated with nocturnal hypoxemia (51). Several cross-sectional studies from diverse populations have demonstrated that OSA is associated with increased prevalence and severity of ocular complications such as retinopathy and maculopathy from type 2 diabetes (52-55). Furthermore, Tahrani et al. (56) showed that the incidence of ocular complications in patients with type 2 diabetes and OSA is higher than in those without OSA.

\section{Effects of OSA Treatment on Diabetes}

Treatment to control the signs and symptoms of OSA includes behavioral approaches to improving sleep habits and weight control. Both medical and surgical weight loss significantly reduce the severity of OSA. More recently, weight loss related to lifestyle interventions in people with type 2 diabetes has been shown to significantly improve OSA severity $(57,58)$. However, it is unclear whether the improvement in OSA (as a result of weight loss) in these studies had an independent effect on control of type 2 diabetes. Other treatments for OSA include ear, nose, and throat or maxillofacial surgeries with the objective of improving the patency of the upper airway. In recent years, maxillary advancement devices, fitted by orthodontists to cause maxillary protrusion, have become increasingly used and studied. Data regarding the effects of these treatment interventions for OSA in type 2 diabetes are limited and beyond the scope of this review.

CPAP treatment is the first-line and most effective treatment for OSA. Randomized, placebo-controlled trials show that CPAP has a beneficial effect on glucose homeostasis in obese and nonobese populations with prediabetes $(59,60)$. In addition, metabolic effects of CPAP versus oral placebo were recently examined in a randomized, controlled study in patients with prediabetes (59). CPAP significantly improved insulin sensitivity by oral GTT and reduced 24-hour blood pressure compared to placebo. These results are consistent with a previous meta-analysis that included only randomized, controlled trials, with a total of -240 patients without type 2 diabetes showing significant improvement 
TABLE 1. CPAP Treatment and Type 2 Diabetes

\begin{tabular}{lcll}
\hline Study & $\begin{array}{l}\text { Sample } \\
\text { Size }(\boldsymbol{n})\end{array}$ & Design & Primary Findings \\
\hline Prasad et al. (62) & 221 & $\begin{array}{l}\text { Retrospective cohort; CPAP effects over 2 } \\
\text { years }\end{array}$ & $\begin{array}{l}\text { No change in A1C before and after CPAP } \\
\text { treatment }\end{array}$ \\
\hline Guest et al. (63) & 300 & $\begin{array}{l}\text { Retrospective case control; CPAP vs. no treat- } \\
\text { ment over 5 years }\end{array}$ & A1C significantly lower in CPAP group \\
\hline Myhill et al. (64) & 44 & $\begin{array}{l}\text { Prospective, randomized; CPAP early (<1 } \\
\text { week) or late ( }>1 \text { month) for 3 months }\end{array}$ & $\begin{array}{l}\text { Decreased insulin resistance in CPAP } \\
\text { group by oral GTT }\end{array}$ \\
\hline Guo et al. (65) & 40 & $\begin{array}{l}\text { Prospective; pre-treatment vs. post-CPAP } \\
\text { treatment for 1 month }\end{array}$ & $\begin{array}{l}\text { Decreased 24-hour mean blood glucose } \\
\text { and nighttime mean blood glucose after } \\
\text { CPAP, as determined by continuous } \\
\text { glucose monitoring }\end{array}$ \\
\hline Salford et al. (66) & 80 & $\begin{array}{l}\text { Prospective, randomized, controlled trial; } \\
\text { CPAP vs. conservative treatment for 3 months }\end{array}$ & $\begin{array}{l}\text { Decreased insulin resistance by oral GTT } \\
\text { in CPAP group }\end{array}$ \\
\hline
\end{tabular}

in HOMA index with CPAP treatment compared to placebo (61).

Table 1 summarizes studies published in the past 5 years that have examined the effects of CPAP treatment on metabolic markers of glucose homeostasis in type 2 diabetes (6266). For a more detailed discussion, including a comprehensive listing of all relevant publications, readers are referred to focused literature reviews and meta-analyses on this topic (67-69).

Although the data regarding effects of CPAP treatment on control of type 2 diabetes remain limited by small sample size or lack of control group, it appears that, overall, CPAP treatment benefits glucose homeostasis in patients with type 2 diabetes. The effect size of CPAP treatment is possibly less than that of weight loss and oral hypoglycemic agents, but it remains clinically significant (70). This effect is enhanced with increased CPAP adherence and is more marked in cases with moderate to severe OSA, obesity, and poorly controlled diabetes $(60,63,71)$. The duration of CPAP treatment exerts significant influence on glucose homeostasis; improvements can be expected to occur after 3 months of treatment. It is important to note that the data supporting the salutary effects of CPAP on glucose homeostasis are more robust in populations with prediabetes than in those with type 2 diabetes. This is partly because a smaller number of studies have addressed this question in populations with type 2 diabetes. However, biologically plausible explanations for this observation include that type 2 diabetes is a more advanced form of dysregulated glucose metabolism (irreversible $\beta$-cell dysfunction) and that patients with established type 2 diabetes are more likely to be older and to have other medical illnesses. These observations suggest that interventions to diagnose and treat OSA in populations with or at risk for type 2 diabetes should be instituted early, and compliance with treatment should be optimized (38).

\section{Conclusion}

In summary, OSA, via sympathetic activation, oxidative stress, inflammation, and neuroendocrine dysregulation, alters glucose homeostasis, including in patients with type 2 diabetes. Early recognition and interventions for OSA can be expected to improve insulin sensitivity and control of hyperglycemia in many patients. Clinicians must remain vigilant for signs and symptoms of OSA and monitor compliance with CPAP along with weight management, diet control, and medication adherence in patients with type 2 diabetes. Important goals of care that require further definition with empirical data include duration of treatment, necessary level of CPAP compliance, effect of alternate OSA treatments such as behavioral and weight loss interventions, and subpopulations with type 2 diabetes most likely to benefit from CPAP treatment.

\section{Acknowledgments}

Dr. Prasad is a recipient of a Career Development Award (CDA2, 1IK2CX001026-01; U.S. Department of Veterans Affairs Clinical Science, Research, and Development [VA CSR\&D]). The views expressed in this article are those of the authors and not those of VA CSR\&D.

\section{Duality of Interest}

No potential conflicts of interest relevant to this article were reported.

\section{References}

1. Rosen, CL, Larkin EK, Kirchner HL, et al. Prevalence and risk factors for sleep-disordered breathing in 8- to 11-year-old children: association with race and prematurity. J Pediatr 2003;142:383-389

2. Young T, Palta M, Dempsey J, Skatrud J, Weber S, Badr S. The occurrence of sleep-disordered breathing among middle-aged adults. N Engl J Med 1993;328:1230-1235

3. Morgenstern M, Wang J, Beatty N, Batemarco T, Sica AAL, Greenberg H. Obstructive sleep apnea: an unexpected cause of insulin resistance and diabetes. Endocrinol Metab Clin North Am 2014:43:187-204

4. Young T, Finn L, Peppard PE, et al. Sleep disordered breathing and mortality: eighteen-year follow-up of the Wisconsin sleep cohort. Sleep 2008;31:1071-1078

5. Perfect MM, Patel PG, Scott RE, et al. Sleep, glucose, and daytime function- 
ing in youth with type 1 diabetes. Sleep 2012;35:81-88

6. Koren D, O'Sullivan KL, Mokhlesi B. Metabolic and glycemic sequelae of sleep disturbances in children and adults. Curr Diab Rep 2015;15:562

7. Polotsky VY, Li J, Punjabi NM, et al. Intermittent hypoxia increases insulin resistance in genetically obese mice. J Physiol 2003;552:253-264

8. Drager LF, Li J, Reinke C, BevansFonti S, Jun JC, Polotsky VY. Intermittent hypoxia exacerbates metabolic effects of diet-induced obesity. Obesity (Silver Spring) 2011;19:2167-2174

9. Polak J, Shimoda LA, Drager LF, et al. Intermittent hypoxia impairs glucose homeostasis in C57BL6/J mice: partial improvement with cessation of the exposure. Sleep 2013;36:1483-1490, 1490A-1490B

10. Savransky V, Bevans S, Nanayakkara A, et al. Chronic intermittent hypoxia causes hepatitis in a mouse model of diet-induced fatty liver. Am J Physiol Gastrointest Liver Physiol 2007;293:G871-G877

11. Yokoe T, Alonso LC, Romano LC, et al. Intermittent hypoxia reverses the diurnal glucose rhythm and causes pancreatic beta-cell replication in mice. J Physiol 2008;586:899-911

12. Xu J, Long YS, Gozal D, Epstein PN. Beta-cell death and proliferation after intermittent hypoxia: role of oxidative stress. Free Radic Biol Med 2009;46:783-790

13. Wang N, Khan SA, Prabhakar NR, Nanduri J. Impairment of pancreatic beta-cell function by chronic intermittent hypoxia. Exp Physiol 2013;98:1376-1385

14. Magalang UJ, Cruff JP, Rajappan R, et al. Intermittent hypoxia suppresses adiponectin secretion by adipocytes. Exp Clin Endocrinol Diabetes 2009;117:129-134

15. Fu C, Jiang L, Zhu F, et al. Chronic intermittent hypoxia leads to insulin resistance and impaired glucose tolerance through dysregulation of adipokines in non-obese rats. Sleep Breath. 2015. Electronically published ahead of print (doi: 10.1007/s11325-015-1144-8)

16. Tamisier R, Pepin jl, Remy j, et al. 14 nights of intermittent hypoxia elevate daytime blood pressure and sympathetic activity in healthy humans. Eur Respir J 2011;37:119-128

17. Prabhakar NR, Kumar GK, Peng YJ. Sympatho-adrenal activation by chronic intermittent hypoxia. J Appl Physiol (1985) 2012;113:1304-1310

18. Louis M, Punjabi NM. Effects of acute intermittent hypoxia on glucose metabolism in awake healthy volunteers. J Appl Physiol (1985) 2009;106:1538-1544

19. Lesser DJ, Bhatia R, Tran WH, et al. Sleep fragmentation and intermittent hypoxemia are associated with decreased insulin sensitivity in obese adolescent Latino males. Pediatr Res 2012;72:293-298

20. Stamatakis KA, Punjabi NM. Effects of sleep fragmentation on glucose metabolism in normal subjects. Chest 2010;137:95-101

21. Tasali E, Leproult R, Ehrmann DA, Van Cauter E. Slow-wave sleep and the risk of type 2 diabetes in humans. Proc Natl Acad Sci U S A 2008;105:1044-1049

22. Pogach MS, Punjabi NM, Thomas N, Thomas RJ. Electrocardiogram-based sleep spectrogram measures of sleep stability and glucose disposal in sleep disordered breathing. Sleep 2012;35:139-148

23. Knutson KL, Van Cauter E, Zee P, Liu K, Lauderdale DS. Cross-sectional associations between measures of sleep and markers of glucose metabolism among subjects with and without diabetes: the Coronary Artery Risk Development in Young Adults (CARDIA) Sleep Study. Diabetes Care 2011;34:1171-1176

24. Resnick HE, Redline S, Shahar E, et al. Diabetes and sleep disturbances: findings from the Sleep Heart Health Study. Diabetes Care 2003;26:702-709

25. Heffner JE, Rozenfeld Y, Kai M, Stephens EA, Brown LK. Prevalence of diagnosed sleep apnea among patients with type 2 diabetes in primary care. Chest 2012;141:1414-1421

26. Foster GD, Sanders MH, Millman R, et al. Obstructive sleep apnea among obese patients with type 2 diabetes. Diabetes Care 2009;32:1017-1019

27. Seicean S, Kirchner HL, Gottlieb DJ, et al. Sleep-disordered breathing and impaired glucose metabolism in normal-weight and overweight/obese individuals: the Sleep Heart Health Study. Diabetes Care 2008;31:1001-1006

28. Punjabi NM, Shahar E, Redline $S$, Gottlieb DJ, Givelber R, Resnick HE. Sleep-disordered breathing, glucose intolerance, and insulin resistance: the Sleep Heart Health Study. Am J Epidemiol 2004; 160:521-530

29. Ip MS, Lam B, Ng MM, Lam WK, Tsang KW, Lam KS. Obstructive sleep apnea is independently associated with insulin resistance. Am J Respir Crit Care Med 2002;165:670-676

30. Borel AL, Monneret D, Tamisier R, et al. The severity of nocturnal hypoxia but not abdominal adiposity is associated with insulin resistance in non-obese men with sleep apnea. PLoS One 2013;8:e71000

31. Lindberg E, Theorell-Haglow J, Svensson M, Gislason T, Berne C, Janson C. Sleep apnea and glucose metabolism: a long-term follow-up in a community-based sample. Chest 2012;142:935-942

32. Reichmuth KJ, Austin D, Skatrud JB, Young T. Association of sleep apnea and type II diabetes: a population-based study. Am J Respir Crit Care Med 2005;172:1590-1595

33. Marshall NS, Wong KK, Phillips CL, Liu PY, Knuiman MW, Grunstein RR. Is sleep apnea an independent risk factor for prevalent and incident diabetes in the Busselton Health Study? J Clin Sleep Med 2009;5:15-20

34. Botros N, Concato J, Mohsenin V, Selim B, Doctor K, Yaggi HK. Obstructive sleep apnea as a risk factor for type 2 diabetes. Am J Med 2009;122:1122-1127

35. Celen YT, Hedner J, Carlson J, Peker Y. Impact of gender on incident diabetes mellitus in obstructive sleep apnea: a 16-year follow-up. J Clin Sleep Med 2010;6:244-250

36. Wang X, Bi Y, Zhang Q, Pan F. Obstructive sleep apnoea and the risk of type 2 diabetes: a meta-analysis of prospective cohort studies. Respirology 2013;18:140-146

37. Chami HA, Gottlieb DJ, Redline S, Punjabi NM. Association between glucose metabolism and sleep-disordered breathing during REM sleep. Am J Respir Crit Care Med. 2015. Electronically published ahead of print (doi: 10.1164/rccm.201501-0046OC)

38. Grimaldi D, Beccuti G, Touma C, Van Cauter E, Mokhlesi B. Association of obstructive sleep apnea in rapid eye movement sleep with reduced glycemic control in type 2 diabetes: therapeutic implications. Diabetes Care 2014;37:355-363

39. Pillai A, Warren G, Gunathilake W, Idris I. Effects of sleep apnea severity on glycemic control in patients with type 2 diabetes prior to continuous positive airway pressure treatment. Diabetes Technol Ther 2011:13:945-949

40. Aronsohn RS, Whitmore H, Van Cauter E, Tasali E. Impact of untreated obstructive sleep apnea on glucose control in type 2 diabetes. Am J Respir Crit Care Med 2010;181:507-513

41. Priou P, Le Vaillant M, Meslier N, et al. Association between obstructive sleep apnea severity and glucose control in patients with untreated versus treated diabetes. J Sleep Res 2015;24:425-431

42. St-Onge MP, Zammit G, Reboussin $\mathrm{DM}$, et al. Associations of sleep disturbance and duration with metabolic risk factors in obese persons with type 2 diabetes: data from the Sleep AHEAD Study. Nat Sci Sleep 2012;4:143-150

43. Tamura A, Kawano Y, Watanabe T, Kadota J. Relationship between the severity of obstructive sleep apnea and impaired glucose metabolism in patients with obstructive sleep apnea. Respir Med 2008;102:1412-1416

44. Eisele HJ, Markart P, Schulz R. Obstructive sleep apnea, oxidative stress, and cardiovascular disease: evidence from human studies. Oxid Med Cell Longev 2015;2015:608438

45. Drager LF, Polotsky VY, Lorenzi-Filho G. Obstructive sleep apnea: an emerg- 
ing risk factor for atherosclerosis. Chest 2011;140:534-542

46. Rice TB, Foster GD, Sanders MH, et al. The relationship between obstructive sleep apnea and self-reported stroke or coronary heart disease in overweight and obese adults with type 2 diabetes mellitus. Sleep 2012;35:1293-1298

47. Adeseun GA, Rosas SE. The impact of obstructive sleep apnea on chronic kidney disease. Curr Hypertens Rep 2010;12:378-383

48. Furukawa S, Saito I, Yamamoto S, et al. Nocturnal intermittent hypoxia as an associated risk factor for microalbuminuria in Japanese patients with type 2 diabetes mellitus. Eur J Endocrinol 2013;169:239-246

49. Leong WB, Nolen M, Thomas GN, Adab P, Banerjee D, Taheri S. The impact of hypoxemia on nephropathy in extremely obese patients with type 2 diabetes mellitus. J Clin Sleep Med 2014;10:773-778

50. Leong WB, Jadhakhan F, Taheri S, Thomas GN, Adab P. The association between obstructive sleep apnea and diabetic kidney disease: a systematic review and meta-analysis. Sleep. Electronically published ahead of print on 31 August 2015 (pii: sp-00037-15)

51. Tahrani AA, Ali A, Raymond NT, et al. Obstructive sleep apnea and diabetic neuropathy: a novel association in patients with type 2 diabetes. Am J Respir Crit Care Med 2012;186:434-441

52. Shiba T, Maeno T, Saishin Y, Hori Y, Takahashi M. Nocturnal intermittent serious hypoxia and reoxygenation in proliferative diabetic retinopathy cases. Am J Ophthalmol 2010;149:959-963

53. West SD, Groves DC, Lipinski HJ, et al. The prevalence of retinopathy in men with type 2 diabetes and obstructive sleep apnoea. Diabet Med 2010;27:423-430

54. Rudrappa S, Warren G, Idris I.

Obstructive sleep apnoea is associated with the development and progression of diabetic retinopathy, independent of conventional risk factors and novel biomarkers for diabetic retinopathy. Br J Ophthalmol 2012;96:1535

55. Banerjee D, Leong WB, Arora T, et al. The potential association between obstructive sleep apnea and diabetic retinopathy in severe obesity: the role of hypoxemia. PLoS One 2013;8:e79521

56. Tahrani AA, Ali A, Raymond NT, et al. Obstructive sleep apnea and diabetic nephropathy: a cohort study. Diabetes Care 2013;36:3718-3725

57. Kline CE, Reboussin DM, Foster GD, et al. The effect of changes in cardiorespiratory fitness and weight on obstructive sleep apnea severity in overweight adults with type 2 diabetes. Sleep. Electronically published ahead of print on 5 October 2015 (pii: sp-00338-15)

58. Kuna ST, Reboussin DM, Borradaile $\mathrm{KE}$, et al. Long-term effect of weight loss on obstructive sleep apnea severity in obese patients with type 2 diabetes. Sleep 2013;36:641-649A

59. Pamidi S, Wroblewski K, Stepien M, et al. Eight hours of nightly continuous positive airway pressure treatment of obstructive sleep apnea improves glucose metabolism in patients with prediabetes: a randomized controlled trial. Am J Respir Crit Care Med 2015;192:96-105

60. Weinstock TG, Wang X, Rueschman $\mathrm{M}$, et al. A controlled trial of CPAP therapy on metabolic control in individuals with impaired glucose tolerance and sleep apnea. Sleep 2012;35:617-625B

61. Iftikhar IH, Khan MF, Das A, Magalang UJ. Meta-analysis: continuous positive airway pressure improves insulin resistance in patients with sleep apnea without diabetes. Ann Am Thorac Soc 2013;10:115-120

62. Prasad B, Carley DW, Krishnan JA, Weaver TE, Weaver FM. Effects of positive airway pressure treatment on clinical measures of hypertension and type 2 diabetes. J Clin Sleep Med 2012;8:481-487

63. Guest JF, Panca M, Sladkevicius E, Taheri S, Stradling J. Clinical outcomes and cost-effectiveness of continuous positive airway pressure to manage obstructive sleep apnea in patients with type 2 diabetes in the U.K. Diabetes Care 2014;37:1263-1271

64. Myhill PC, Davis WA, Peters KE, Chubb SA, Hillman D, Davis TM. Effect of continuous positive airway pressure therapy on cardiovascular risk factors in patients with type 2 diabetes and obstructive sleep apnea. J Clin Endocrinol Metab 2012;97:4212-4218

65. Guo LX, Zhao X, Pan Q, et al. Effect of continuous positive airway pressure therapy on glycemic excursions and insulin sensitivity in patients with obstructive sleep apnea-hypopnea syndrome and type 2 diabetes. Chin Med J (Engl) 2015;128:2301-2306

66. Salford N, Fortuna AM, Monasterio C, et al. A randomized controlled trial of continuous positive airway pressure on glucose tolerance in obese patients with obstructive sleep apnea. Sleep. Electronically published ahead of print on 31 August 2015 (pii: sp-00651-14)

67. Gallegos L, Dharia T, Gadegbeku AB. Effect of continuous positive airway pressure on type 2 diabetes mellitus and glucose metabolism. Hosp Pract (1995) 2014;42:31-37

68. Martinez-Ceron E, Fernandez-Navarro I, Garcia-Rio F. Effects of continuous positive airway pressure treatment on glucose metabolism in patients with obstructive sleep apnea. Sleep Med Rev 2016;25:121-130

69. Feng Y, Zhang Z, Dong ZZ. Effects of continuous positive airway pressure therapy on glycaemic control, insulin sensitivity and body mass index in patients with obstructive sleep apnoea and type 2 diabetes: a systematic review and meta-analysis. NPJ Prim Care Respir Med 2015;25:15005

70. Chirinos JA, Gurubhagavatula i, Teff $\mathrm{k}$, et al. CPAP, weight loss, or both for obstructive sleep apnea. N Engl J Med 2014:370:2265-2275

71. Babu AR, Herdegen J, Fogelfeld L, Shott S, Mazzone T. Type 2 diabetes, glycemic control, and continuous positive airway pressure in obstructive sleep apnea. Arch Intern Med 2005;165:447-452 